\title{
HAN-SHOU LIU
}

L. CARPENTER

R.W. AGREEN

\section{JUNE 1973}


PLATE MOTION AND THE SECULAR SHIFT OF THE MEAN POLE

Han-Shou Liu

L. Carpenter

R. W. Agreen

Geodynamics Branch

GODDARD SPACE FLIGHT CENTER

Greenbelt, Maryland 


\author{
PLATE MOTION AND THE SECÚLAR SHIFT \\ OF THE MEAN POLE \\ Han-Shou Liu \\ L. Carpenter \\ R.W. Agreen \\ Geodynamics Branch
}

\begin{abstract}
Recent development of the global plate motion indicates that changes in the products of inertia of the earth due to tectonic plate movement may provide a secular shift of the mean pole. In this paper we present a mathematical procedure for calculating this shift based on the plate theory. Explicit expressions are obtained for the dependence of the secular polar shift on the dimensions and locations of the plate boundaries. Numerical results show that the secular motion of the mean pole is $0 ! 0002$ year $^{-1}$ in the direction of $67^{\circ} \mathrm{W}$. Hence, it is deduced that the influence of the plate motion on the secular polar shift may account for $10 \%$ of the observed value.
\end{abstract}


CONTENTS

$\underline{\text { Page }}$

INTRODUCTION. ........................ 1

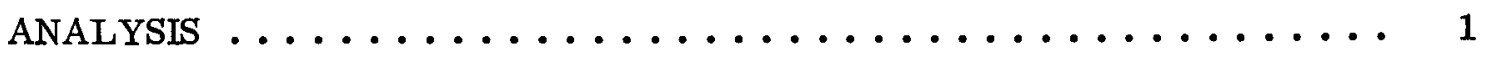

CHANGES IN INERTIA $\ldots \ldots \ldots \ldots \ldots \ldots \ldots \ldots \ldots \ldots$

SHIFT OF THE INERTIA CENTER ............... 6

RESULTS OF COMPUTATIONS $\ldots \ldots \ldots \ldots \ldots \ldots \ldots \ldots \ldots$

DISCUSSTON $\ldots \ldots \ldots \ldots \ldots \ldots \ldots \ldots \ldots \ldots \ldots \ldots \ldots \ldots \ldots \ldots \ldots \ldots$

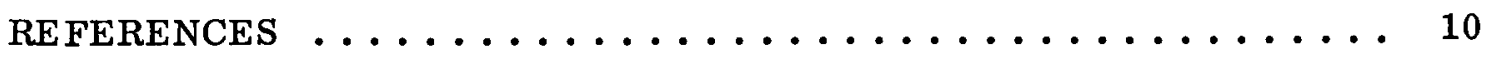


PLATE MOTION AND THE SECULAR SHIFT OF THE MEAN POLE INTRODUCTION

The analysis of the concurrent observations of the International Latitude Service shows that the mean pole of the earth has a secular motion which consists of a progressive component of about $0 !^{\prime} 0035 \mathrm{yr}^{-1}$ along the meridan $65^{\circ} \mathrm{W}$. (Markowitz, 1968). Subtracting the apparent motion of the mean pole due to the local drift, the secular motion of the mean pole is $0:^{\prime} 0022 \mathrm{yr}^{-1}$ in the direction 77:7W (Yumi and Wako, 1968). This mean pole, obtained from a suitable combination of the polar coordinates covering several years with the periodic components of the annual and Chandlerian motion removed, is the pole of inertia of the earth (Melchior, 1972). Recently, Kane (1972) and Bostrom (1971) have proposed a link between polar motion and plate tectonics. They have suggested that movement of the lithosphere consisting of irregular plates as described by Morgan (1968), LePichon (1968), Isacks, et al. (1968), may lead to changes in the location of the principal axes of inertia of the earth and hence to drifting of the pole. The purpose of the present paper is to analyze the influence of the global tectonic plate motion on the shifting of the pole of inertia or the mean pole of the earth.

ANALYSIS

A general analysis is required to determine the position of the principal axes of the earth when the motion of the lithospheric plates is considered. We take a reference system oxyz as principal axes of the earth about which its 
moments of inertia are A, B, and C. Let the lithospheric plates undergo a small movement, which turns the principal axes through angles $\xi, \zeta$ and $\eta$ about the reference axes and makes the new principal moments of inertia $A^{\prime}, B^{\prime}$ and $C^{\prime}$, about the new principal axes $x^{\prime}, y^{\prime}$ and $z^{\prime}$. Because of the plate motion we may define the moments and products of inertia about the reference axes as $\mathrm{A}+\mathrm{a}, \mathrm{B}+\mathrm{b}, \mathrm{C}+\mathrm{c}$ and $\mathrm{E}, \mathrm{F}, \mathrm{G} . \quad$ Then it is required to find $\xi, \zeta$ and $\eta$ in terms of these quantities.

We denote $\ell, \mathrm{m}$ and $\mathrm{n}$ as the direction cosines of a line through the center of the earth with respect to the reference axes. Let $l+\Delta l, m+\Delta m$ and $n+\Delta n$ be the direction cosines of this line with respect to the new principal axes. Then the connection between moments and products of inertia with respect to the two sets of axes through the center of the earth is governed by (Wittaker, 1944).

$$
\begin{aligned}
& \mathrm{A}^{\prime}(\ell+\Delta l)^{2}+\mathrm{B}^{\prime}(\mathrm{m}+\Delta \mathrm{m})^{2}+\mathrm{C}^{\prime}(\mathrm{n}+\Delta \mathrm{n})^{2} \\
& =(\mathrm{A}+\mathrm{a}) \ell^{2}+(\mathrm{B}+\mathrm{b}) \mathrm{m}^{2}+(\mathrm{C}+\mathrm{c}) \mathrm{n}^{2}-2 \mathrm{Emn}-2 \mathrm{Fn} \ell-2 \mathrm{G} \ell \mathrm{m}
\end{aligned}
$$

and

$$
\begin{aligned}
\Delta l & =\eta \mathrm{m}-\zeta \mathrm{n} \\
\Delta \mathrm{m} & =\xi \mathrm{n}-\eta \mathrm{l} \\
\Delta \mathrm{n} & =\zeta \mathrm{l}-\xi \mathrm{m}
\end{aligned}
$$

By substituting equation (2) in equation (1), we obtain

$$
\begin{aligned}
& A^{\prime} \ell^{2}+B^{\prime} m^{2}+C^{\prime} n^{2}-2 m n\left(C^{\prime}-B^{\prime}\right) \xi-2 n \ell\left(A^{\prime}-C^{\prime}\right) \zeta-2 \ell m\left(B^{\prime}-A^{\prime}\right) \eta \\
& =(A+a) \ell^{2}+(B+b) m^{2}+(C+c) n^{2}-2 E m n-2 F n \ell-2 G \ell m
\end{aligned}
$$

to the first order of small quantities. 
Equation (3) holds for all values of $\ell, m$, and $n$.

Hence

$$
\begin{aligned}
& \mathrm{A}^{\prime}=\mathrm{A}+\mathrm{a} \text { for } \ell=1 \text { and } \mathrm{m}=\mathrm{n}=0 \\
& \mathrm{~B}^{\prime}=\mathrm{B}+\mathrm{b} \text { for } \mathrm{m}=1 \text { and } \ell=\mathrm{n}=0 \\
& \mathrm{C}^{\prime}=\mathrm{C}+\mathrm{c} \text { for } \mathrm{n}=1 \text { and } \ell=\mathrm{m}=0 .
\end{aligned}
$$

Thus

$$
\begin{aligned}
& \xi=\frac{E}{C^{\prime}-B^{\prime}}=\frac{E}{(C-B)+(c-b)} \\
& \zeta=\frac{F}{A^{\prime}-C^{\prime}}=\frac{-F}{(C-A)+(c-a)} \\
& \eta=\frac{G}{B^{\prime}-A^{\prime}}=\frac{G}{(B-A)+(b-a)}
\end{aligned}
$$

For the case $B=A$, the axes of reference may always be so chosen that $G$ is absolutely zero because all axes in the xy plane were originally principal axes. Consequently, equation (5) becomes

$$
\begin{aligned}
\xi & =\frac{E}{(C-A)+(c-a)} \\
\xi & =\frac{-F}{(C-A)+(c-a)} \\
\eta & =0
\end{aligned}
$$

Therefore the inclination, $i$, between the new and old principal axes of $z^{\prime}$ and $z$ is

$$
i=\frac{\left(E^{2}+F^{2}\right)^{\frac{1}{2}}}{(C-A)+(c-a)}
$$

and the displacement of the new principal axis $z^{\prime}$ along the meridian measured from the plane of $\mathrm{xz}$ is

$$
\theta=\pi+\tan ^{-1}\left(\frac{\mathrm{E}}{\mathrm{F}}\right)
$$


Equations (7) and (8) express the magnitude and direction of the deflection of the polar axis of the earth in terms of changes in the moments and products of inertia which may be caused by the tectonic plate motion.

\section{CHANGES IN INE RTIA}

The effect of plate motion in deflecting the pole is equivalent to the movement of a given quantity of matter from one part on the surface of the earth to another. According to the plate theory, the past and present positions of the oceanic ridges and trenches and their heights and depths give some idea of the amount of matter at disposal. It is required, therefore, to determine the magnitude and direction of the possible deflection of the pole which can be caused by the movement of given quantities of matter from one part of the earth to another, subject to the conditions of the height, depth and position of plate boundaries. For the present purpose, it is immaterial what may be the forces which produce the plate motion; but it is assumed that the plate motion proceeds with uniform velocity.

In the process of plate motion the earth may be considered as composed of the original ellipsoid, together with a superposed layer of material which is positive in oceanic ridges and negative in oceanic trenches. If we take axes with origin at the center of the ellipsoid and symmetrical thereto, and let $h \Phi(\zeta, \lambda)$ represent the depth of this layer at point $\zeta, \lambda$, where $\zeta$ is the co-latitude and $\lambda$ is longitude, the integral of $\Phi(\zeta, \lambda)$ over the surface of the ellipsoid should be zero because the volume of the earth remains constant. Then by describing 
$\mathrm{h} \Phi(\zeta, \lambda)$ along plate boundaries, the mass redistribution of tectonic plates may be expressed. In order to calculate the products and moments of inertia due to plate motion, we use spherical coordinates: $\mathrm{x}=\mathrm{r} \operatorname{Sin} \zeta \operatorname{Cos} \lambda, \mathrm{y}=\mathrm{r} \operatorname{Sin} \zeta \operatorname{Sin} \lambda$, $\mathrm{z}=\mathrm{r} \operatorname{Cos} \zeta$, where $\mathrm{r}$ is the radius of the earth. An element of volume in these coordinates is $\mathrm{dV}=\mathrm{r}^{2} \operatorname{Sin} \zeta \mathrm{d} \zeta \mathrm{d} \lambda \mathrm{dr}$. Therefore the changes in products and moments of inertia due to plate motion are

$$
\begin{aligned}
& \mathrm{E}=\mathrm{h} \rho \mathrm{r}^{4} \int_{\ell_{3}}^{l_{4}} \int_{l_{1}}^{l_{2}} \Phi(\zeta, \lambda) \operatorname{Sin}^{2} \zeta \operatorname{Cos} \zeta \operatorname{Sin} \lambda \mathrm{d} \zeta \mathrm{d} \lambda \\
& \mathrm{F}=\mathrm{h} \rho \mathrm{r}^{4} \int_{\ell_{3}}^{\ell_{4}} \int_{\ell_{1}}^{l_{2}} \Phi(\zeta, \lambda) \operatorname{Sin}^{2} \zeta \operatorname{Cos} \zeta \operatorname{Cos} \lambda \mathrm{d} \zeta \mathrm{d} \lambda \\
& \mathrm{a}=\mathrm{h} \rho \mathrm{r}^{4} \int_{\ell_{3}}^{\ell_{4}} \int_{\ell_{1}}^{\ell_{2}} \Phi(\zeta, \lambda) \operatorname{Sin} \zeta\left(\operatorname{Sin}^{2} \zeta \operatorname{Sin}^{2} \lambda+\operatorname{Cos}^{2} \zeta\right) \mathrm{d} \zeta \mathrm{d} \lambda \\
& \mathrm{c}=\mathrm{h} \rho \mathrm{r}^{4} \int_{\ell_{3}}^{\ell_{4}} \int_{\ell_{1}}^{\ell_{2}} \Phi(\zeta, \lambda) \sin ^{3} \zeta \mathrm{d} \zeta \mathrm{d} \lambda
\end{aligned}
$$

where $\rho$ is the density of the surface of the earth, $\Phi(\zeta, \lambda)$ is a function to determine if mass is added by the plate motion or removed and $\ell_{1}, \ell_{2}, \ell_{3}$ and $\ell_{4}$ are limits on the plate boundaries.

For the estimation of the secular shift of the mean pole, a computer program is developed to follow the evolution of the products and moments of inertia of the earth. $\Phi(\zeta, \lambda)$ may be chosen such that it is zero at the limits of integration. In this case a double application of the trapezoidal rule (Hildebrand, 1956) gives 


$$
\begin{aligned}
& E=h \rho r^{4} \frac{\left(\ell_{4}-\ell_{3}\right)\left(\ell_{2}-\ell_{1}\right)}{(N+1)(M+1)} \sum_{i=1}^{M} \sum_{k=1}^{N}\left[\Phi\left(\zeta_{k}, \lambda_{i}\right) \operatorname{Sin}^{2} \zeta_{k} \operatorname{Cos} \zeta_{k} \operatorname{Sin} \lambda_{i}\right] \\
& F=h \rho r^{4} \frac{\left(\ell_{4}-\ell_{3}\right)\left(\ell_{2}-\ell_{1}\right)}{(N+1)(M+1)} \sum_{i=1}^{M} \sum_{k=1}^{N}\left[\Phi\left(\zeta_{k}, \lambda_{i}\right) \operatorname{Sin}^{2} \zeta_{k} \operatorname{Cos} \zeta_{k} \operatorname{Cos} \lambda_{i}\right] \\
& a=h \rho r^{4} \frac{\left(\ell_{4}-\ell_{3}\right)\left(\ell_{2}-\ell_{1}\right)}{(N+1)(M+1)} \sum_{i=1}^{M} \sum_{k=1}^{N}\left[\Phi\left(\zeta_{k}, \lambda_{i}\right) \operatorname{Sin} \zeta_{k}\left(\operatorname{Sin}^{2} \zeta_{k} \operatorname{Sin}^{2} \lambda_{i}+\operatorname{Cos}^{2} \zeta_{k}\right]\right. \\
& c=h \rho r^{4} \frac{\left(\ell_{4}-\ell_{3}\right)\left(\ell_{2}-\ell_{1}\right)}{(N+1)(M+1)} \sum_{i=1}^{M} \sum_{k=1}^{N}\left[\Phi\left(\zeta_{k}, \lambda_{i}\right) \operatorname{Sin}^{3} \zeta_{k}\right]
\end{aligned}
$$

where

$$
\begin{aligned}
& \zeta_{k}=\frac{k\left(l_{2}-l_{1}\right)}{N+1}+l_{1}, \\
& \lambda_{i}=\frac{j\left(l_{4}-l_{3}\right)}{M+1}+l_{3} .
\end{aligned}
$$

which are coded for computation by a computer. The formalism outlined here can be also applied for the estimation of polar motion due to the inertia changes arising over shorter time scales from the accumulation of ground water by diverting the flow of large rivers (Batrakov, 1972).

\section{SHIFT OF THE INERTIA CENTER}

In the derivation of equations (7), (8) and (10), we have assumed that the earth's center of inertia is fixed at the origin. However, during the process of plate motion, the coordinates $\left(x_{1}, y_{1}, z_{1}\right)$ of the inertia center are shifted by

$$
\begin{aligned}
& \mathrm{x}_{1}=\frac{\mathrm{h} \rho \mathrm{r}^{3}}{\mathrm{M}} \iint \Phi(\zeta, \lambda) \operatorname{Sin}^{2} \zeta \operatorname{Cos} \lambda \mathrm{d} \zeta \mathrm{d} \lambda \\
& \mathrm{y}_{1}=\frac{\mathrm{h} \rho \mathrm{r}^{3}}{\mathrm{M}} \iint \Phi(\zeta, \lambda) \operatorname{Sin}^{2} \zeta \operatorname{Sin} \lambda \mathrm{d} \zeta \mathrm{d} \lambda \\
& \mathrm{z}_{1}=\frac{\mathrm{h} \rho \mathrm{r}^{3}}{\mathrm{M}} \iint \Phi(\zeta, \lambda) \operatorname{Sin} \zeta \operatorname{Cos} \lambda \mathrm{d} \zeta \mathrm{d} \lambda
\end{aligned}
$$

where $M=\frac{4}{3} \pi \rho_{m} r^{3}$ is the mass of the earth and $\rho_{m}$ is the mean density. 
The products and moments of inertia of the earth about axes parallel to $x, y$, and $z$ through $\left(x_{1}, y_{1}, z_{1}\right)$ in the process of plate motion are

$$
\begin{aligned}
& \mathrm{A}^{\prime}=\mathrm{A}+\mathrm{a}-\mathrm{M}\left(\mathrm{y}_{1}{ }^{2}+\mathrm{z}_{1}{ }^{2}\right)=\mathrm{A}+\mathrm{a}\left(1-\frac{\alpha}{\mathrm{a}}\right) \\
& \mathrm{B}^{\prime}=\mathrm{B}+\mathrm{b}-\mathrm{M}\left(\mathrm{x}_{1}{ }^{2}+\mathrm{z}_{1}{ }^{2}\right)=\mathrm{B}+\mathrm{b}\left(1-\frac{\beta}{\mathrm{b}}\right) \\
& \mathrm{C}^{\prime}=\mathrm{C}+\mathrm{C}-\mathrm{M}\left(\mathrm{x}_{1}{ }^{2}+\mathrm{y}_{1}{ }^{2}\right)=\mathrm{C}+\mathrm{c}\left(1-\frac{\gamma}{\mathrm{c}}\right) \\
& \mathrm{E}^{\prime}=\mathrm{E}-\mathrm{My}_{1} \mathrm{z}_{1}=\mathrm{E}\left(1-\frac{\epsilon}{\mathrm{E}}\right) \\
& \mathrm{F}^{\prime}=\mathrm{F}-\mathrm{Mx}_{1} \mathrm{z}_{1}=\mathrm{F}\left(1-\frac{\mathrm{f}}{\mathrm{F}}\right)
\end{aligned}
$$

From equations (9), (11) and (12) we note that the ratio of $\frac{\alpha}{\mathrm{a}}, \frac{\beta}{\mathrm{b}}, \frac{\gamma}{\mathrm{c}}, \frac{\epsilon}{\mathrm{E}}$ and $\frac{\mathbf{f}}{\mathrm{F}}$ varies as $h / r$. The crest of oceanic ridges stands several $\mathrm{km}$ higher than the flanking abyssal plains (Van Bemmelen, 1972); hence $\mathrm{h} / \mathrm{r}$ is in the order of $10^{-3}$. Therefore, the changes in products and moments of inertia due to the shift of the inertia center by plate motion is negligible, and the application of equations (7), (8), (9) and (10) for the estimation of the polar motion is justified.

\section{RESULTS OF COMPUTATIONS}

To make the problem entirely determined we follow the ideas of LePichon (1968), Morgan (1968) and Isacks, et al. (1968) to divide the earth's surface into plates which stay undeformed except at their boundaries where material may be added or moved. This simplification will lead to the mathematical solution which can be considered as an approximate solution to the actual problem of the redistribution of mass on the surface of the earth due to tectonic plate motion. 
During the sea-floor spreading process, which occurs at oceanic ridges, new crust is generated along plate boundaries. At the deep oceanic trenches, plate boundaries are destructive. Chase (1972) and Deffeyes (1970) have calculated the rate of crustal flux on the plate boundaries. According to their result, a surface area of $5.867 \mathrm{~km}^{2}$ is involved in the creation and destruction of lithosphere each year in connection with plate motion.

The world-encircling mid-ocean ridge system is a topographic rise, thousands of kilometers in width and tens of thousands of kilometers in length. If we assume that the net thickness of the lithospheric material which is created along the oceanic ridges is $3 \mathrm{~km}$, then the total volume of lithosphere which is displaced is $17.6 \mathrm{~km}^{3}$ annually. These data were used to compute the corresponding products and moments of inertia as described previously.

In the process of computation, the following parameters and coefficients are used (Allen, 1963)

$$
\begin{array}{ll}
\mathrm{A}=0.3295 \mathrm{Mr}_{1}{ }^{2}, & \mathrm{C}=0.3306 \mathrm{Mr}_{1}{ }^{2}, \\
\mathrm{M}=5.977 \times 10^{27} \mathrm{~g} ., & \mathrm{r}_{1}=6378.17 \mathrm{~km} ., \\
\rho=2.64 \mathrm{~g} \cdot \mathrm{cm}^{-3}, & \mathrm{r}=6371.03 \mathrm{~km} .
\end{array}
$$

Taking these data, we have calculated the magnitude and direction of the secular shift of the mean pole of the earth by means of equations (7), (8) and (10). The results are $\mathrm{i}=0 !^{\prime} 0002 \mathrm{yr}^{-1}$ and $\theta=67^{\circ} \mathrm{W}$. 


\section{DISCUSSION}

Markowitz (1968) has studied and discussed the reality of the observed secular change of the position of the mean pole by assuming that the positions of the International Latitude Service stations did not change with each other. However, the real change in mean latitude of any station which is expected from a supposed movement related to plate motion would produce an apparent change of the mean pole (Kaula, 1970). Arur and Mueller (1971) and Mueller and Schwarz (1972) have attempted to isolate the observed secular motion of the mean pole from plate motion and investigated to what extent the secular change is compatible with plate theory. No conclusion can be drawn from their study because of the limited available data of large uncertainties. The effect of earthquakes on the polar motion (Mansinha and Smylie, 1967) may at most account for 30 percent of the observed secular polar shift (Ben-Menahem and Isreal, 1970). Moreover, no attempt seems to have been made to explain the influence of the site and azimuth of an earthquake on the direction of the secular polar. motion; and this point should indeed be considered as an essential one (Melchior, 1972). In the present paper we have formulated the effect of plate movement on both the magnitude and direction of secular polar motion. The changes in the products and moments of inertia of the earth due to plate motion are computed for mass redistribution along plate boundaries that have been analyzed in the literature. From the changes in the products of inertia, the contribution to the resulting polar shift is calculated. Applying the plate 
theory, we arrived at an annual secular polar shift of 0!0002 in the direction $67^{\circ} \mathrm{W}$. The theoretical foundation of this study is based upon an extremely simple rigid global plate model of the earth. In order to make progress in this direction, it is indispensable to describe the global tectonic plates in terms of rheology (Van Bremmelen, 1972) which could change considerably the order of magnitude of the estimated effects. Finally, since the degree of correlation between our result and observed secular motion of the mean pole seems to be highly dependent on data used, better fundamental observation of polar motion with new methods as developed by Smith, et al. (1972) is needed.

\section{RE FERENCES}

Allen, C.W. Astrophysical Quantities, Athlone Press, University of London, London, 1963.

Arur, M. G. and I. I. Mueller, Latitude Observations and the Detection of Continental Drift, J. Geophys. Res. 76, 2071, 1971.

Batakov, Y.V., Effect of Diverting the Flow of Siberian Rivers upon the Rotation of the Earth, Soveit Astronomy, A. J. 15, 5, 853-857, 1972. Ben-Menahem, A. and M. Isreal, Effects of Major Seismic Events on the Rotation of the Earth, Geophys. J. Roy. Astr. Soc., 19, 367-393, 1970. Bostrom, R. C., Westward Displacement of the Lithosphere, Nature, 234, $536-538,1971$.

Chase, C. C., The N-Plate Problem on Plate Tectonics, Geophys. J. Roy. Astr. Soc. , 29, 117-122, 1972. 
Deffeyes, K. S., The Axial Valley a steady-state feature of the terrain, in the Megatectonics of Continents and Oceans, p. 194, eds. H. Johnson and B. L. Smith, Rutgers University Press, 1970 .

Hildebrand, J. B. , Introduction to Numerical Analysis, McGraw Inc. , 71-73, 1956. Isacks, B. J., Oliver, and L. R. Sykes, Seismology and the New Global Tectonics, J. Geophys. Res. 73, 5855, 1968.

Kane, M. F., Rotational Inertia of Continents: A Proposed Link between Polar Wandering and Plate Tectonics, Science, 175, 1355-1357, 1972.

Kaula, W. M. (ed.), Solid Earth and Ocean Physics, Report of a study at Williamstown, Massachusetts, sponsored by NASA Electronic Research Center and M. I. T. Measurement Systems Laboratory, 1970.

LePichon, X., Sea-floor Spreading and Continental Drift, J. Geophys. Res., $73,3661,1968$.

Markowitz, Wm., Concurrent Astronomical Observations for Studying Continental Drift, Polar Motion, and the Rotation of the Earth, In: Continental Drift, Secular Motion of the Pole, and Rotation of the Earth, edited, by Wm. Markowitz and B. Guinot, Reidel, Dordrecht, 25-32, 1968. Mansinha, L. and D. E. Smylie, Effects of Earthquakes on the Chandler Wobble and Secular. Polar Shift, J. Geophys. Res. , 72, 18, 4731-4743, 1967. Melchior, P., Earth Tides and Polar Motion, In: The Upper Mantle, Tectonophysics edited by A. R. Ritsema, 13 (1-4), 361-372, 1972. 
Morgan, W.J., Rise, Trenches, Great Faults and Crustal Blocks, J. Geophys. Res., 73, 1959, 1968.

Mueller, I. I. , and C. R. Schwarz, Separating the Secular Motion of the Pole from Continental Drift: Where and What to Observe, In: Rotation of the Earth, edited by P. Melchior and S. Yumi, Reidel, Dordrecht, 1972.

Smith, D. E., R. Kolenkiewicz, P. Dunn, H.H. Plotkin and T.S. Johnson, Polar Mitiun from Laser Tracking of Artificial Satellites, Science, $178,405-406,1972$.

Yumi, S. and Y. Wako, on the Secular Motion of the Mean Pole, In: Continental Drift, Secular Motion of the Pole, and Rotation of the Earth, edited by Wm. Markowitz and B. Guinot, Reidel, Dordrecht, 33-36, 1968.

Van Bemmelen, R. R., Developments in Geotectonics 2: Geodynamic Models, Elserier, New York, 1972.

Wittaker, F. T., A Treatise on the Analytical Dynamics, Dover, New York, 1944. 